\title{
Hugo Chávez y los principios del Socialismo del Siglo XXI: una indagación discursiva (2005-2013)*
}

\author{
Hugo Chávez and the principles of Socialism of the 21st Century: a discursive \\ inquiry (2005-2013)
}

\author{
Paula Vidal Molina** - Manuel Ansaldo Roloff ${ }^{* * *}$ - Juan Carlos Cea Madrid ${ }^{* * * *}$
}

\begin{abstract}
Resumen: En el presente artículo se puntualizan - en un plano teórico - las ideas fuerza del Socialismo del Siglo XXI que dan cuenta de un debate inacabado en el plano político. Considerando las orientaciones ideológicas expresadas en los discursos de Hugo Chávez (2005 - 2013), se analizan los elementos de continuidad y ruptura en su vertiente latinoamericana que constituyen el Socialismo Bolivariano. A partir de estos componentes, el artículo presenta una clave de lectura situada en torno al ideario socialista con el objetivo de reflexionar sobre su relevancia y vigencia en la época contemporánea.
\end{abstract}

Palabras claves: Socialismo del Siglo XXI, Socialismo Bolivariano, Hugo Chávez, Venezuela.

\begin{abstract}
This article specifies the key ideas of Socialism of the 21st century - at a theoretical level - which consider an unfinished political debate. Considering the ideological orientations expressed in the speeches of Hugo Chávez (2005-2013), the elements of continuity and rupture in his Latin-American perspective which constitute Bolivarian Socialism are analyzed. Based on these components, the article presents a key
\end{abstract}

\footnotetext{
* Este trabajo forma parte del Proyecto FONDECYT REGULAR N ${ }^{\circ} 1160742$ "Planes sociales de empleo y protección social para la (des)igualdad: los casos de Brasil, Chile y Venezuela (2005-2013)". Agradecemos a a la Dra. Xiomara Rodríguez, de la Universidad de Zulia, en Venezuela quien es la contraparte venezolana para efectos de este proyecto de investigación-en el contexto de colaboración internacional- y con quien compartimos y reflexionamos varias de las ideas aquí contenidas, durante su estadía en Chile en el mes de agosto de 2017. Agradecemos también a Conicyt-Fondecyt.

** Chilena. Autora principal. Trabajadora Social, Pontificia Universidad Católica de Chile. Magíster en Antropología y Desarrollo, Universidad de Chile. Doctora en Servicio Social, Universidade Federal de Río de Janeiro. Académica área de Trabajo Social, Facultad de Ciencias Sociales, Universidad de Chile. Investigadora Responsable Proyecto FONDECYT REGULAR N 1160742 "Planes sociales de empleo y protección social para la (des)igualdad: los casos de Brasil, Chile y Venezuela (2005-2013)". pvidal@u.uchile.cl

${ }_{* * * *}$ Chileno. Coautor. Sociólogo, Pontificia Universidad Católica de Chile. Magister en Sociología, FLACSO Ecuador. Ayudante de investigación Proyecto FONDECYT REGULAR N ${ }^{\circ} 1160742$. manoloansaldo@gmail.com

***** Chileno. Coautor. Psicólogo, Universidad de Santiago de Chile. Estudiante del Magister en Psicología, mención Psicología Comunitaria, Universidad de Chile. Tesista del Proyecto FONDECYT REGULAR N ${ }^{\circ}$ 1160742. jcarlos.ceamadrid@gmail.com
} 
interpretation situated around socialist ideas with the objective of reflecting on the relevance and validity in our contemporary era.

Key words: Socialism of the 21st century, Bolivarian Socialism, Hugo Chávez, Venezuela.

Recibido: 3 diciembre 2017

Aceptado: 2 febrero 2018

\section{1.- Introducción}

Diversos poderes hegemónicos sostienen que las sociedades, bajo el dominio de políticas neoliberales, pueden ofrecer desarrollo humano para el conjunto de la población. Sin embargo, después de la crisis económica del año 2008, comenzó a expandirse una elaboración crítica, tanto desde el campo académico-intelectual como desde el políticoinstitucional y los movimientos sociales, para hacer frente a las recomendaciones y orientaciones económicas impulsadas por organismos globales. Previamente a esta crisis, desde fines de la década de 1990 y entrados los años 2000, procesos sociales en algunos países latinoamericanos, mostraron indicios de una crítica a la implementación de políticas neoliberales y comenzaron a construir una nueva hegemonía. Este es el legado de Hugo Chávez y el proceso de constitución de la República Bolivariana de Venezuela.

Para el año 2005, Hugo Chávez hablaba de "Socialismo del siglo XXI" y situaba en el concierto de los países latinoamericanos, un concepto para reflexionar sobre sus bases teóricas y su articulación a procesos sociales concretos. Como sabemos, Marx no dejó un cuerpo teórico ni modelo acabado sobre la transición hacia el socialismo y la sociedad comunista, es decir, dejó un campo abierto que le toca construir a cada pueblo y sociedad. En este sentido, estudiar y comprender la transición hacia la sociedad socialista y comunista, tanto en el plano teórico como lo realizado en el proceso histórico concreto, cobra importancia para establecer continuidades, rupturas, errores y aciertos hacia un horizonte de desarrollo pleno de los seres humanos y los pueblos.

Rescatar críticamente este legado e identificar las diversas modalidades y expresiones que dan cuenta del socialismo, especialmente la denominación de "Socialismo del Siglo XXI" a través de la visión de Hugo Chávez, es parte de las reflexiones y aprendizajes que deben hacerse, no solo por la importancia y protagonismo de su trayectoria política, sino también a la luz de la situación político-económica y social que ha vivido la República Bolivariana de Venezuela, después de su muerte.

Desde el año 2014 a la fecha, se han agudizado contradicciones y conflictos que tienen al país en un momento histórico de suma complejidad, donde se juega la restauración de las fuerzas conservadoras y el orden neoliberal o la defensa y -de ser posible- la profundización de las medidas impulsadas a favor de las demandas por derechos sociales, 
políticos, económicos y culturales de los sectores subalternos ${ }^{1}$. En esta coyuntura, cabe resaltar dos aspectos fundamentales del proceso vivido y construido por el pueblo venezolano:

a) los logros y avances obtenidos para los sectores subalternos de la sociedad -en los planos político y socio-económico- por los gobiernos de Chávez, mostrados por organismos internacionales como la $\mathrm{CEPAL}^{2}$ o el PNUD ${ }^{3}$.

b) rescatar los principios e ideas declaradas como rectoras del Socialismo del Siglo $\mathrm{XXI}$, que ayuden a reflexionar sobre los fundamentos que lo rigen y las razones de su defensa a la hora de emprender el camino de su construcción histórica en la sociedad.

Lo señalado se complejiza, en la medida en que -a nivel teórico- existen diversas interpretaciones sobre los principios que rigen el significado de socialismo, e incluso, se problematiza si los argumentos y principios declarados como referencia de este proyecto, refieren propiamente a un "Socialismo del siglo XXI" y que aspectos lo caracterizarían.

En este marco, cobra sentido y significación reconstruir -en el plano teóricoalgunas ideas fuerza del socialismo del Siglo XXI derivadas del pensamiento de Hugo Chávez, lo cual permite dialogar y establecer diferencias y similitudes con otros autores e intelectuales de referencia en este tema, identificando el sello particular que caracterizaría la senda venezolana, que puede comprenderse como una expresión singular del Socialismo del Siglo XXI: Socialismo Bolivariano. Así, es posible sostener la hipótesis que Chávez, cuando se refiere a la noción de Socialismo del siglo XXI, plantea una variante o particularización de este concepto, el cual sería una construcción propia, lo cual enriquece y da un carácter situado a las definiciones señaladas por diversos autores sobre Socialismo del Siglo XXI.

Al respecto, cabe señalar que la producción científico-académica de la última década ha dejado un vacío en este ámbito, ya que si bien, una revisión bibliográfica sobre Hugo Chávez y la Revolución Bolivariana hasta el 2010 ya mostraba más de 2.564 publicaciones impresas ${ }^{4}$, muy menor es la cantidad de publicaciones que tratan el socialismo del siglo XXI en Venezuela, con alrededor de 300 artículos y libros rastreados en bases de datos de acceso abierto en idiomas castellano e inglés, entre los años 2005 y 2016.

De estos, las temáticas más estudiadas remiten a un análisis crítico de la tradición rentista de la economía venezolana, problematizando su matriz extractivista, la dependencia

\footnotetext{
${ }^{1}$ Al respecto ver Daniel Chávez, Hernán Ouviña y Mabel Thwaites Rey (Eds.), Venezuela. Lecturas urgentes desde el sur, Amsterdam y Buenos Aires, CLACSO, 2017.

${ }^{2}$ Comisión Económica para América Latina y el Caribe (CEPAL), Protección social y generación de empleo: análisis de experiencias derivadas de programas de transferencias con corresponsabilidad, Santiago, Naciones Unidas, 2011.

${ }^{3}$ El año 2015 Venezuela se ubica en el grupo de países de "Desarrollo Humano alto" en el lugar $71^{\circ}$, sobre países como México $74^{\circ}$, Brasil $75^{\circ}$ y Colombia $97^{\circ}$. Ver Programa de las Naciones Unidas para el Desarrollo (PNUD), Informe sobre desarrollo humano 2015, Trabajo al servicio del desarrollo humano, Estados Unidos, PNUD, 2015.

${ }^{4}$ Leticia Rodríguez, El discurso de Hugo Chávez (1999-2009): Una década de hegemonía comunicacional y revival propagandístico, Memoria para optar al grado de Doctor. Departamento de Historia de la Comunicación Social, Facultad de ciencias de la información, Universidad Complutense de Madrid, 2012.
} 
del petróleo ${ }^{5}$, así como las restricciones para la creación de fuentes de ingreso alternativas y de producción ${ }^{6}$. Otros ámbitos estudiados se relacionan con las tensiones para garantizar la seguridad alimentaria y una agricultura sustentable ${ }^{7}$, así como las contradicciones en el desarrollo de un plan de extracción minera ecosustentable con las resistencias de los movimientos sociales ${ }^{8}$. A su vez, se presentan una serie de publicaciones que destacan en el ámbito laboral la prohibición de la tercerización, el fortalecimiento de las empresas de producción social, y el proceso de cambios en una economía social con participación de las comunidades bajo los principios del cooperativismo y la autogestión ${ }^{9}$.

Por otro lado, una serie de publicaciones han expresado diversas críticas al sistema político venezolano, cuestionando el desarrollo del sistema electoral, la desaparición de las libertades ciudadanas y la falta de independencia de los poderes públicos ${ }^{10}$, dando cuenta de un eventual deterioro institucional y crisis de gobernabilidad en Venezuela. A su vez, atributos como personalismo mesiánico, gobierno autocrático con rasgos totalitarios y democracia populista ${ }^{11}$ serían algunas características del período chavista. En contraste, diversos autores destacan los avances de la democracia participativa en los campos de planificación urbana, ordenamiento territorial y participación popular durante el gobierno de Chávez $^{12}$, sin embargo, también problematizan las implicancias de la participación

5 Margarita López-Maya y Luis Lander "El socialismo rentista de Venezuela ante la caída de los precios petroleros internacionales", Cuadernos del CENDES, 26(71), 2009, 67-87; José Honorio, "La política petrolera del gobierno Chávez o la redefinición del Estado ante la globalización neoliberal", Historia Actual Online, (24), 2011, 7-15.

${ }^{6}$ Edgardo Lander, La implosión de la Venezuela rentista, Amsterdam, Transnational Institute (TNI), 2016; Carlos Peña (comp.), Venezuela y su tradición rentista: visiones, enfoques y evidencias, Buenos Aires y Caracas, CLACSO - Universidad Central de Venezuela, 2017.

7 Laura Enríquez y Simeon Newman, "The conflicted state and agrarian transformation in pink tide Venezuela", Journal of Agrarian Change, 16(4), 2016, 594-626; Thomas Purcell, "The political economy of rentier capitalism and the limits to agrarian transformation in Venezuela", Journal of Agrarian Change, 17(2), 2017, 296-312.

8 María García-Guadilla, "Dilemas del ecosocialismo post-neoliberal y resistencia de los movimientos sociales frente al modelo neo-extractivista en Venezuela", Revista Encuentros Latinoamericanos, 8(2), 2104, 3-47; Emiliano Terán Mantovani, "El extractivismo en la Revolución Bolivariana: "potencia energética mundial" y resistencias eco-territoriales", Iberoamericana, 15(59), 2015, 111-125.

9 Darío Azzellini, "Economía solidaria, formas de propiedad colectiva, nacionalizaciones, empresas socialistas, co-y autogestión en Venezuela" Revista ORG \& DEMO, 10(1/2), 2010, 5-30; Thomas Purcell, "The Political Economy of Social Production Companies in Venezuela" Latin American Perspectives, 40(3), 2013, 146-168; Verónica González, "De la prohibición de la tercerización hacia el fortalecimiento de los modelos socio productivos: ¿Alternativas para la transformación del Estado venezolano?”, Gaceta Laboral, 22(2), 2016, 123-143.

${ }^{10}$ Miriam Kornblith, "Venezuela: calidad de las elecciones y calidad de la democracia". América Latina Hoy, (45), 2007, 109-124; Laura Louza, "La estrecha y necesaria relación entre independencia judicial, estado de derecho, el respeto de los derechos humanos y democracia. Venezuela como caso de estudio", Acta Sociológica, (72), 2017, 95-127.

${ }^{11}$ Nelly Arenas, "La Venezuela de Hugo Chávez: rentismo, populismo y democracia", Nueva Sociedad, 229, 2010, 76-94; Ryan Brading, "From passive to radical revolution in Venezuela's populist Project", Latin American Perspectives, 41(6), 2014, 48-64.

12 Jesús Machado, "Participación social y consejos comunales en Venezuela", Revista Venezolana de Economía y Ciencias Sociales, 15(1), 2009, 173-185; Rosa Corina, "Una mirada al Ordenamiento Territorial en Venezuela en el Marco del Ecosocialismo”, Ciencias Espaciales, 9(1), 2016, 185-199; Becker Sánchez, 
ciudadana en los procesos de centralización y descentralización, así como los alcances y limitaciones del poder popular ${ }^{13}$.

En un punto intermedio entre estas perspectivas polarizadas, una serie de artículos se hacen cargo del debate teórico e ideológico en torno al proyecto político del socialismo del siglo XXI en Venezuela, el análisis de la transición sociopolítica con el ascenso de Chávez al poder, así como una evaluación global del proyecto bolivariano ${ }^{14}$. Finalmente, diversas publicaciones indagan en la vida y obra política de Hugo Chávez ${ }^{15}$, en particular, sus discursos, utilizando diversos enfoques y metodologías para describir la presencia de valores ideológicos y su contexto de producción ${ }^{16}$, redes de metáforas conceptuales y $\operatorname{cognitivas}^{17}$, el vínculo entre política y religión ${ }^{18}$, la generación de identidades políticas ${ }^{19}$, así como la construcción de una narrativa revolucionaria ${ }^{20}$. No obstante lo anterior, llama la atención que este tipo de análisis de los discursos no considera la disputa de ideas en el proyecto societario que lidera Chávez.

Si bien existe una gran producción académica que aborda la figura de Hugo Chávez y/o la construcción socio-histórica del proceso bolivariano, se invisibilizan -en el análisis global o local, coyuntural o personalista- aquellos principios ideológicos del Socialismo del Siglo XXI presentes en la producción discursiva del líder venezolano, elementos que caracterizarían una perspectiva singular y situada del proyecto socialista bolivariano. De esta forma, este artículo busca contribuir en torno a este vacío teórico y para ello,

"El rediseño socio-institucional y la acción colectiva: La experiencia venezolana de la Democracia Participativa y Protagónica del Modelo Socialista de Hugo Chávez”. Espacio Abierto, 2016, 25(1).

${ }^{13}$ Rosangel Alvarez, "El poder popular en el espacio comunal venezolano: ¿descentralización o centralismo?” Cadernos do Tempo Presente, (26), 2017, 3-27; María García-Guadilla, "La praxis de los consejos comunales en Venezuela: ¿Poder popular o instancia clientelar?”, Revista Venezolana de Economía y Ciencias Sociales, 14(1), 2008, 125-151.

${ }^{14}$ Luis Bilbao, Venezuela en revolución: renacimiento del socialismo, Buenos Aires, Capital Intelectual, 2008; Iain Bruce, The Real Venezuela: Making Socialism in the 21st Century, London, Pluto Press, 2008; Mario Ayala y Pablo Quintero (comps.), Diez años de revolución en Venezuela: historia, balance y perspectivas (1999-2009), Buenos Aires, Editorial Maipue, 2009; Steve Ellner, "Hugo Chávez’s first decade in office: Breakthroughs and shortcomings", Latin American Perspectives, 37(1), 2010, 77-96.

15 Elvira Narvaja, El discurso latinoamericanista de Hugo Chávez, Buenos Aires, Biblos, 2008; Mike Gonzalez, Hugo Chavez: Socialist for the Twenty-first Century, London, Pluto Press, 2014.

16 Blanca Méndez, "Análisis Hermenéutico del discurso del ex presidente Hugo Chávez: El Nuevo Mapa Estratégico a partir del contexto político Ideológico 'Contra hegemonía y Socialismo del Siglo XXI"”, Reflexión Política, 17(33), 2015, 64-76; Juan Romero y Yessica Quiñónez, "El pensamiento socio-político de Chávez: discurso, poder e historia (1998-2009)", Espacio Abierto, 20(3), 2011, 519-536.

17 Thays Adrián, "La metáfora conceptual en el discurso político venezolano: Rómulo Betancourt y Hugo Chávez Frías". Revista de la Asociación Latinoamericana de Estudios del Discurso, 10(1), 2010, 9-33; Irma Chumaceiro, "Las metáforas políticas en el discurso de dos líderes venezolanos: H. Chávez \& E. Mendoza" Revista Latinoamericana de Estudios del Discurso, 4(2), 2004, 91-113; Mercedes Duarte, "Funciones estratégicas de las redes de metáforas en torno a "socialismo": Un análisis interaccional del discurso político de Hugo Chávez”, Revista signos, 49(90), 2016, 24-47.

${ }^{18}$ Cristián Rojas, "La persistencia del lenguaje religioso en el discurso político: El caso de Hugo Chávez", Civilizar Ciencias Sociales y Humanas, 13(24), 157-164.

${ }^{19}$ Héctor Hurtado, "Una mirada al discurso populista de Hugo Chávez: tensiones entre la ruptura y la tradición”, Aposta. Revista de Ciencias Sociales, (66), 2015, 38-61.

${ }^{20}$ Miguel Martínez y Rebeca Vaisberg, "La narrativa revolucionaria del Chavismo”, Postdata, 19(2), 2014, 463-506. 
metodológicamente desde un enfoque cualitativo, se presenta un trabajo de selección de textos de diverso tipo -artículos, libros, discursos- de Hugo Chávez, correspondientes a los años 2005-2013 y posteriormente, un análisis de contenido mediante la utilización del software Nvivo.

A continuación, el lector encontrará apartados que dan cuenta de una aproximación conceptual al "Socialismo del siglo XXI", una configuración de los principios que rigen este proyecto político en el debate contemporáneo, junto a un análisis de la propuestavariante configurada por Hugo Chávez: Socialismo Bolivariano.

\section{Origen y el paso ininterrumpido (deriva) de un concepto: el Socialismo del Siglo XXI}

Desde fines de la década de los 90’, en América Latina se van a gestar procesos políticos progresistas que van a poner en cuestión la hegemonía neoliberal. La hazaña venezolana -con la figura de Hugo Chávez- y el proceso bolivariano iniciado, ayudó a cambiar la situación geopolítica latinoamericana, a favor de las clases subalternas ${ }^{21}$ situando en el escenario un nuevo término: Socialismo del siglo XXI. Pero, ¿Qué significa Socialismo del siglo XXI?, ¿Cuáles son sus bases teórico-ideológicas? ¿A quiénes define como sus protagonistas sociales y políticos? ¿Cuáles son sus instituciones fundamentales? Estas interrogantes implican identificar el contexto de aparición de este concepto, los contrapuntos en relación al legado del socialismo, para luego situar el significado particular que representa al calor de los discursos de Hugo Chávez.

Diversos autores contemporáneos ${ }^{22}$ tienden a coincidir en que este término aparece desde una crítica tanto a la experiencia de los llamados socialismos realmente existentes, como en el plano teórico a la reificación y reduccionismo sufrido por la teoría marxista. Por un lado, esto implica hacer cuentas con el pasado de los "socialismos reales" y enfrentar críticamente sus componentes como la falta de democracia, el totalitarismo, el capitalismo de Estado, la planificación central y burocrática, el colectivismo entendido como anulación de las diferencias, el productivismo sin límites frente a los límites de la naturaleza, el dogmatismo e intolerancia a la divergencia, el partido único en la conducción del proceso de transición, el mantenimiento de la lógica del capital como forma de relación con la producción y el trabajo, o dicho de otro modo, la linealidad del progreso y/o etapismo en el avance hacia el socialismo, un esencialismo economicista y la ingenua creencia en que nacionalizar los medios de producción es socializar estos, la falta de participación y protagonismo de las clases subalternas en las cuestiones de definiciones políticas, en

\footnotetext{
${ }^{21}$ Marta Harnecker, Un mundo a construir: nuevos caminos, Santiago de Chile, LOM Ediciones, 2014.

22 Tomas Moulian, Socialismo del siglo XXI: La quinta vía, Santiago de Chile, LOM Ediciones, 2000; Heinz Dieterich, Socialismo del Siglo XXI, 2002, En https://www.rebelion.org/docs/121968.pdf; Juan Carlos Monedero, "Hacia una filosofía política del socialismo del siglo XXI. Notas desde el caso venezolano", Cuadernos del CENDES, 25(68), 2008, 71-106; István Mészáros, El desafío y la carga del tiempo histórico: el socialismo del siglo XXI, Caracas, Vadell Hermanos Editores, 2008; Michael Lebowitz, The Contradictions of «Real Socialism». The Conductor and the Conducted, New York, Monthly Review Press, 2012.
} 
definitiva, la creencia en que el modelo de la Unión Soviética podía replicarse en cualquier parte del mundo.

Frente a estos límites del socialismo (en el siglo XX), diversos autores han planteado una crítica al modo de producción capitalista y su fase neoliberal (con sus consecuencias), y con ello aparece el problema de la transición hacia el socialismo, como una suerte de etapa posterior a la sociedad actual y previa a una sociedad plenamente socialista. Todos estos elementos señalan una necesidad de superar las formas en que lo económico, lo político, lo social y lo cultural se relacionan y determinan en un orden específicamente capitalista.

Alejados de un modelo único, serían estos elementos parte constitutiva de la transición al Socialismo del Siglo XXI. Al respecto, Dieterich ${ }^{23}$ señala que el paso hacia el Socialismo del Siglo XXI implica un medio de superación de los sistemas económicos y políticos actuales. En concreto, plantea que el actual sistema económico posee cinco limitaciones sistémicas: es inestable, asimétrico, de carácter mercantil-nacionalista, con transnacionales que controlan la economía de forma excluyente $y$, finalmente, es ecológicamente imposible. Ante esto, propone una economía de equivalencias y "democráticamente planificada", es decir, donde los intercambios de los sujetos económicos se realicen sobre valores iguales o cantidad de trabajo y esfuerzos laborales iguales aportados a la generación de riqueza social. Por otro lado, en el campo político, Dieterich habla de Democracia Directa y Participativa, para superar la democracia burguesa formal y la relaciona con "la capacidad real de la mayoría ciudadana de decidir sobre los principales asuntos públicos de la nación”24.

Por otra parte, el sujeto emancipador, para Dieterich, no es solo la clase obrera, como se creyó durante el siglo XX, sino todos aquellas víctimas del capitalismo neoliberal reunidas en un campo multicultural, pluriétnico, policlasista, global y de géneros y "abarca a todos aquellos que coincidan en la necesidad de democratizar a fondo la economía, la política, la cultura y los sistemas de coerción física de la sociedad mundial"25. A su vez, Marta Harnecker coincide en la idea que el "Socialismo del Siglo XXI" implica una democracia social y política en que la ciudadanía es la "que conquista, que toma decisiones; que ejecuta y controla; que autogestiona, que autogobierna [...] La participación, el protagonismo en todos los espacios, es lo que permite a la persona crecer, ganar autoconfianza, es decir, desarrollarse humanamente" 26 . Asimismo, estos rasgos se conjugan con potenciar la "autonomía y descentralización en la toma de decisiones", para evitar la burocratización del Estado.

En el plano económico, Marta Harnecker señala que el "Socialismo del siglo XXI", se caracteriza por poner en su centro la persona, pues se rige por una lógica humanista y solidaria orientada a la satisfacción de las necesidades humanas y no a la obtención de lucro. Además, respeta la naturaleza y lucha contra el consumismo, ella dirá, nuestra meta no debe ser "vivir mejor" sino "vivir bien"27. En este sentido, Harnecker, sigue las

${ }^{23}$ Dieterich, op. cit.

${ }^{24}$ Ibid. p., 48

${ }^{25}$ Ibid. p.,58

${ }^{26}$ Harnecker, op.cit. p.,84

${ }^{27}$ Ibid. p.,98-101 
contribuciones de Michael Lebowitz respecto de la producción, quien plantea que esta debe responder a una planificación participativa y estar orientada a la satisfacción de las necesidades, respetando a la naturaleza bajo el uso racional de los recursos naturales y buscando el pleno desarrollo humano. Respecto de los medios de producción, se plantea la propiedad social, lo cual no es equivalente a que el Estado pase a ser el propietario legal de estos medios, sino que los trabajadores se apropien del proceso de producción y participen en las diversas etapas de este, aportando su pensamiento-conocimiento y su hacer ${ }^{28}$.

Por otra parte, Mészáros coincide con lo señalado al destacar como núcleo central del "Socialismo del Siglo XXI", la progresiva transferencia de la toma de decisiones a los productores asociados, expresado en la participación democrática y propiedad colectiva de los medios de producción ${ }^{29}$. Otro aspecto central en el "Socialismo del Siglo XXI" es la discusión respecto a la planificación, la que se entiende como oposición al despilfarro y destrucción del mercado capitalista, en la medida que el capital subordina el valor de uso al valor de cambio (acá se pueden considerar como un elemento complementario las críticas al crecimiento capitalista que no consideran el respeto al medio ambiente). El socialismo real habría sostenido una planificación centralizada de la economía desde el Estado, en cambio, el énfasis del socialismo del siglo XXI se encuentra en la propiedad colectiva de los medios de producción bajo los principios de la autogestión ${ }^{30}$.

Para Monedero el "Socialismo del Siglo XXI" es un sistema de organización que busca la libertad y la justicia, la solidaridad entre los miembros de la comunidad, la defensa de las diferencias, el respeto medioambiental, la paz entre las naciones e iguales condiciones para todos los pueblos del mundo ${ }^{31}$. A su vez, este sería una metáfora para nombrar el proyecto histórico del socialismo en un nuevo siglo, en donde -por medio de las experiencias acumuladas- se entiende la existencia de socialismos en plural, lo cual contempla la creación colectiva de nuevos lenguajes, y la construcción de una nueva ciudadanía que vaya más allá del concepto de ciudadano propio de liberalismo ${ }^{32}$. Monedero, sintetiza los trazos que caracterizan al Socialismo del Siglo XXI, señalando que este -a diferencia del neoliberalismo- se identifica, entre otras cosas, con un Cosmopolitismo multicultural y plurinacional, asimismo, considera la comunidad y la autonomía colectiva como instancias que controlan popularmente las dependencias y aparato del Estado ${ }^{33}$.

A partir de lo anterior, se ha elaborado la siguiente tabla que sintetiza los puntos de encuentro y los matices particulares respecto a las nociones del "Socialismo del Siglo XXI" de los autores anteriormente revisados, los cuales convergen en 5 aspectos claves: Democracia, Sujetos Históricos, Formas de Producción e Intercambio, Naturaleza y Planificación:

\footnotetext{
${ }^{28}$ Lebowitz, op cit. p., 45-46

${ }^{29}$ Mészáros, op.cit. p. , 380

${ }^{30}$ Ibid. p.385

${ }^{31}$ Monedero, op. cit. p., 79

${ }^{32}$ Ibid. p., 76-80

${ }^{33}$ Ibid. p., 83
} 


\begin{tabular}{|c|c|c|c|c|c|}
\hline & \multicolumn{2}{|c|}{ Política } & \multicolumn{3}{|c|}{ Económica } \\
\hline & $\begin{array}{l}\text { Democracia } \\
\text { Directa/ } \\
\text { participativa/ } \\
\text { protagónica }\end{array}$ & $\begin{array}{l}\text { Nuevo Sujeto } \\
\text { Histórico }\end{array}$ & $\begin{array}{l}\text { Nuevas } \\
\text { formas de } \\
\text { producción e } \\
\text { intercambio }\end{array}$ & $\begin{array}{l}\text { Respeto a la } \\
\text { naturaleza }\end{array}$ & Planificación \\
\hline Dieterich & $\begin{array}{l}\text { Democracia } \\
\text { Directa y } \\
\text { participativa: } \\
\text { Decisión } \\
\text { permanente de } \\
\text { la mayoría en } \\
\text { los asuntos } \\
\text { públicos de la } \\
\text { nación. }\end{array}$ & $\begin{array}{l}\text { Víctimas del } \\
\text { capitalismo } \\
\text { neoliberal a } \\
\text { escala global } \\
\text { Plurales } \\
\text { sujetos }\end{array}$ & $\begin{array}{l}\text { Combinar } \\
\text { teoría del } \\
\text { valor del } \\
\text { trabajo con el } \\
\text { principio de } \\
\text { equivalencia }\end{array}$ & $\begin{array}{l}\text { Control } \\
\text { socialista de } \\
\text { la } \\
\text { explotación } \\
\text { de la } \\
\text { naturaleza } \\
\text { que sea } \\
\text { sustentable } \\
\text { en el tiempo }\end{array}$ & $\begin{array}{l}\text { Planificación } \\
\text { democrática: } \\
\text { Soberanía } \\
\text { ciudadana }\end{array}$ \\
\hline Harnecker & $\begin{array}{l}\text { Democracia } \\
\text { social y } \\
\text { política: } \\
\text { autogobierno } \\
\text { popular. } \\
\text { Protagonismo } \\
\text { y participación }\end{array}$ & $\begin{array}{l}\text { Plurales } \\
\text { sujetos }\end{array}$ & $\begin{array}{l}\text { Lógica } \\
\text { humanista y } \\
\text { solidaria: } \\
\text { necesidades } \\
\text { humanas }\end{array}$ & & $\begin{array}{l}\text { Democrática y } \\
\text { participativa }\end{array}$ \\
\hline Lebowitz & $\begin{array}{l}\text { Participación } \\
\text { y democracia }\end{array}$ & $\begin{array}{l}\text { Trabajador/ } \\
\text { Productor en } \\
\text { el centro del } \\
\text { sistema } \\
\text { socialista }\end{array}$ & $\begin{array}{l}\text { Propiedad } \\
\text { social/Particip } \\
\text { ación en la } \\
\text { producción } \\
\text { por parte de } \\
\text { los } \\
\text { trabajadores }\end{array}$ & $\begin{array}{l}\text { Uso racional } \\
\text { de } \quad \text { los } \\
\text { recursos } \\
\text { naturales y } \\
\text { humanos }\end{array}$ & $\begin{array}{l}\text { Planificación } \\
\text { participativa } \\
\text { desde los } \\
\text { productores }\end{array}$ \\
\hline Mészáros & $\begin{array}{l}\text { Igualdad } \\
\text { sustantiva: } \\
\text { Participación } \\
\text { democrática }\end{array}$ & & $\begin{array}{l}\text { Igualdad } \\
\text { sustantiva: } \\
\text { Propiedad } \\
\text { colectiva de } \\
\text { los medios de } \\
\text { producción }\end{array}$ & $\begin{array}{l}\text { Cuidado de } \\
\text { los recursos } \\
\text { del planeta }\end{array}$ & $\begin{array}{l}\text { Productores } \\
\text { libremente } \\
\text { asociados }\end{array}$ \\
\hline Monedero & $\begin{array}{l}\text { Construcción } \\
\text { colectiva de } \\
\text { una nueva } \\
\text { ciudadanía }\end{array}$ & $\begin{array}{l}\text { El pueblo } \\
\text { empoderado/ } \\
\text { multicultural } \\
\text { y } \\
\text { plurinacional }\end{array}$ & $\begin{array}{l}\text { Trabajador } \\
\text { produce lo } \\
\text { material y el } \\
\text { mundo de la } \\
\text { vida (lo } \\
\text { subjetivo) }\end{array}$ & $\begin{array}{l}\text { Respeto } \\
\text { medioambie } \\
\text { ntal }\end{array}$ & $\begin{array}{l}\text { Comunidades } \\
\text { controlan al } \\
\text { Estado }\end{array}$ \\
\hline
\end{tabular}

Elaboración propia en función de las lecturas de los autores 


\section{Hugo Chávez y el Socialismo del Siglo XXI como Socialismo Bolivariano}

En términos masivos, el concepto "Socialismo del siglo XXI" adquirió difusión mundial a partir de su mención por el entonces presidente de Venezuela, Hugo Chávez, el año 2005:

Entonces si no es el capitalismo ¿Qué? Yo no tengo duda, es el socialismo. Ahora ¿qué socialismo? ¿cuál de tantos? Pudiéramos pensar incluso que ninguno de los que han sido, aun cuando hay experiencias, hay logros y avances en muchos casos de socialismo, tendremos que inventárnoslo y de allí la importancia de estos debates y de esta batalla de ideas; hay que inventar el Socialismo del siglo XXI y habrá que ver por qué vías, muchas vías, lo sabemos, lo táctico es tan variado como la mente de cada uno de nosotros ${ }^{34}$

Al analizar los discursos de Chávez, el "Socialismo del siglo XXI" refiere a algunos trazos que permiten diferenciarlo de la experiencia de los socialismos reales del siglo XX y define un carácter particular, pues habla de la transformación económica, democracia participativa y protagónica en lo político, un socialismo que no responde a la copia de modelos externos para implantarse en la realidad de cada país, sino una creación propia. En concreto, al profundizar en los discursos de Hugo Chávez se pueden identificar -al menoslas siguientes características del Socialismo del Siglo XXI y que dan forma a su Socialismo Bolivariano, las cuales son posibles de ordenar en siete dimensiones:

3.1. Dimensión ético-moral. En el discurso de Chávez adquieren relevancia valores que se encuentran en las antípodas de los promovidos por la sociedad capitalista como el egoísmo, el consumismo y el individualismo. Algunos de los valores que destacan son la solidaridad, el amor, el sacrificio por los otros y la igualdad, los cuales no son formales ni abstractos, sino que concretos. Estos poseen puntos de encuentro con las enseñanzas del cristianismo. Chávez lo expresa claramente cuando señala que:

Estamos infectados de los valores viejos, del egoísmo, del capitalismo, de la fragmentación de la sociedad. Nos envenenaron desde niños. Vamos por ese veneno y vamos a hacernos un exorcismo [...] Ustedes tienen que comenzar desde abajo, potenciando el amor social, la conciencia del deber social, así lo resumo. Es el frente moral. Los valores del socialismo son, para mí, así lo digo, tal cual los principios del verdadero cristianismo: la igualdad, el amor por los demás, el sacrificarse uno, incluso, por los demás. Eso es imposible en el capitalismo, por eso creo que Cristo fue uno de los más grandes socialistas de la historia. ${ }^{35}$

${ }^{34}$ Hugo Chávez, Selección de discursos del Presidente de la República Bolivariana de Venezuela Hugo

${ }^{35}$ Hugo Chávez, Las comunas y los cinco frentes para la construcción del socialismo. Aló Presidente Teórico $N^{\circ}$ 1, Caracas, Ediciones MinCi, 2009, p., 9. 
Hay que leer los discursos de Cristo y su acción vital, antiimperialista, enfrentado a las élites del poder económico, político y religioso de su tiempo. Pregonaba la igualdad, la libertad del ser humano, su dignidad, su dignificación. Terminó yendo al martirio por los pobres de la Tierra $[\ldots]$ El verdadero reino de Cristo no es otro que el socialismo. ${ }^{36}$

La igualdad, no es posible en el marco del capitalismo, y dentro del campo éticomoral, es relevada por el Socialismo ${ }^{37}$, que Chávez reconoce como aporte no solo de Marx (señalado en su escrito: Crítica del Programa de Gotha), sino también de Simón Bolívar ("semilla" de la liberación de América de la dominación española). Si bien, considera que todos los seres humanos son desiguales por naturaleza, la sociedad socialista debe igualar las condiciones de vida ofrecidas a toda la población, donde cada uno aportará según sus capacidades. Hugo Chávez lo expresa así:

Hay un principio de cada quien según sus capacidades, y a cada quien según sus necesidades. Eso irá igualándonos. Al que más puede dar hay que pedirle más; al que más necesite hay que apoyarlo más, y eso irá generando la igualdad. Porque somos desiguales por naturaleza, así lo dijeron Bolívar y Carlos Marx. El socialismo trata de colocarnos en un ámbito de igualdad en la sociedad. Una igualdad ficticia, decía Bolívar, pero es una igualdad social, una igualdad política, una igualdad ética. Porque aun cuando nacemos desiguales y somos diversos - no somos autómatas ni somos robots para ser idénticos-, luego vienen las leyes, decía Bolívar, las artes, el conocimiento, la educación, la cultura, la industria, y nos colocan en un clima de igualdad de condiciones de vida. ${ }^{38}$

En ese sentido, la dimensión ético-moral no es formal sino concreta, pues no se desarrolla en un individuo aislado sino colectivamente en la sociedad, territorio, geografía y unidad como es la Comuna (volveremos sobre esto más adelante), donde es posible construir una identidad en que se plasmen los valores de la sociedad socialista:

Los socialistas debemos ser portadores del amor, de la vida del cuerpo colectivo, de la mente colectiva, de la solidaridad, del compromiso y de la conciencia del deber social; y ustedes deben ser mucho mejor que nosotros, mil veces mejor que nosotros, el ejemplo de verdaderos revolucionarios socialistas [...] Nosotros defendemos la propiedad social, la propiedad del pueblo, la propiedad personal, la propiedad honesta, la propiedad de tu trabajo, la propiedad de tu vivienda, la propiedad de ti

\footnotetext{
${ }^{36}$ Hugo Chávez, El socialismo del siglo XXI, Caracas, Ediciones MinCi, 2011, p.22.

${ }^{37}$ La igualdad ha sido objeto de estudios en el campo de la izquierda y el marxismo durante el último tiempo, para detalles sobre este tema, revisar en esta misma revista los artículos de Paula Vidal, en los Números 9 y 18.

${ }^{38}$ Hugo Chávez, 2009, op. cit. p., 9. 
mismo, la propiedad de tus bienes personales, la propiedad familiar, la propiedad comunal." ${ }^{39}$

A partir de lo anterior, podemos sintetizar las ideas de la dimensión ético-moral, en la siguiente figura:

Figura $\mathrm{N}^{\circ}$ 1. Dimensión ético-moral ${ }^{40}$.

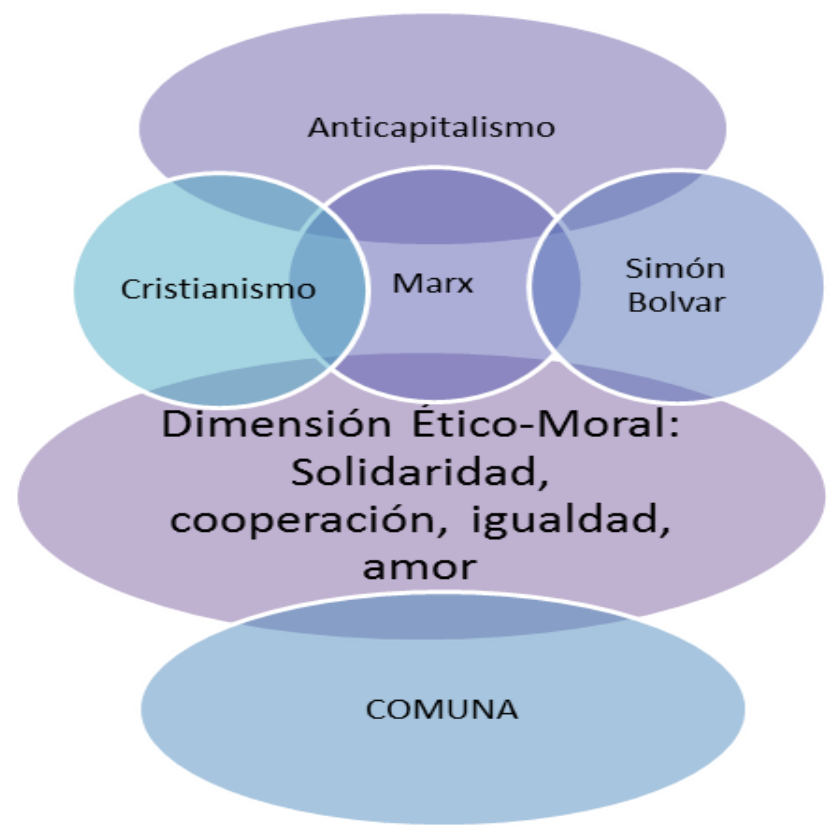

3.2.- Dimensión de los saberes latinoamericanos. Una tradición que se incorporaba en parte en la dimensión anterior, es la de los padres independentistas latinoamericanos. Sobre este último punto, Chávez articula el "Socialismo del siglo XXI" con lo que denomina el "árbol de las tres raíces" o el triángulo conformado por tres de los que considera los más grandes pensadores y revolucionarios de América Latina y Venezuela: Simón Rodríguez o Samuel Robinson, Simón Bolívar y Ezequiel Zamora, con quienes recupera las ideas de supranacionalismo, unidad latinoamericana, dignidad y soberanía para el pueblo. Chávez así los expresa cuando señala:

Ocho años después ratifico el juramento, ahora sobre nuestra maravillosa Constitución Bolivariana, y ahora, lanzándolo hacia el futuro: Construir la vía venezolana al socialismo; construir el socialismo venezolano. En ello se nos irá la vida, toda la vida, pero no me cabe la menor duda de que ese es el único camino a la redención de nuestro pueblo, a la salvación de nuestra Patria y a la construcción de nuestro mundo donde se haga

\footnotetext{
${ }^{39}$ Hugo Chávez, 2011, op. cit. p., 41, 111, 112.

${ }^{40}$ Elaboración propia en función de los discursos de Hugo Chávez. Las siguientes figuras que aparecen en el artículo también cumplen con esta característica.
} 
realidad el sueño de tantos y de tantas, y aquellos de Bolívar en Angostura: La mayor suma de felicidad posible. ${ }^{41}$

Chávez reconoce la herencia de las luchas del pasado de los venezolanos por su liberación, así como la necesidad de recobrar esta memoria histórica. Las raíces propias y enseñanzas de los héroes nacionalistas para aportar a las luchas del presente, en el camino hacia el socialismo:

¿Cuál es la razón por la que estamos aquí y ahora anunciando y promoviendo cambios profundos al comenzar la última década de este siglo "perdido"? (...) Sin embargo, todas las que aquí pudieran señalarse serían tributarias de una misma corriente, cuyo cauce viene de muy lejos y cuyo lecho aparece y desaparece de manera intermitente en los recovecos y vueltas, casi siempre oscuros, de la historia patria. Existe entonces, compatriotas, una sola y poderosa razón: es el proyecto de Simón Rodríguez, El Maestro; Simón Bolívar, El Líder; y Ezequiel Zamora, El General del Pueblo Soberano; referencia verdaderamente válida y pertinente con el carácter socio-histórico del ser venezolano, que clama nuevamente por el espacio para sembrarse en el alma nacional y conducir su marcha hacia la vigésimo primera centuria. El clamor se hace indetenible por los caminos de Venezuela. Se acerca, se hace torrente y se confunde en el estremecimiento del pueblo venezolano. Este proyecto ha renacido de entre los escombros y se levanta ahora, a finales del siglo $\mathrm{XX}^{42}$

De Simón Rodríguez o llamado de Samuel Robinson, Hugo Chávez rescata lo que denomina el Modelo Robinsoniano que significa la necesidad de no copiar modelos de otras sociedades, esto es:

El estudio del modelo, desde su génesis hasta su desarrollo, demuestra que tal estructura permanece inalterable y obedece a la misma disyuntiva de inventar nuevas instituciones para las nacientes repúblicas latinoamericanas o de errar el camino cayendo en el simplismo de copiar modelos de otros tiempos, otras actitudes, otros hombres. Es decir, si no inventamos, caemos fatalmente en el error. En Sociedades Americanas (1842), Simón Rodríguez se encarga de delinear la disyuntiva: “¿Dónde iremos a buscar modelos? La América española es original. Originales han de ser sus instituciones y su gobierno. Y originales, los medios de fundar uno y otro. O inventamos o erramos. ${ }^{43}$

${ }^{41}$ Hugo Chávez, La construcción del Socialismo del Siglo XXI: discursos del Comandante Supremo ante la Asamblea Nacional (1999-2012). Tomo III (2005-2008), Caracas, Fundación Fondo Editorial de la Asamblea Nacional - Escuela de Formación Integral de la Asamblea Nacional "Dr. Carlos Escarrá Malavé" (Eficem), 2014a, p., 233.

${ }^{42}$ Hugo Chávez, El libro azul, Caracas, Ediciones MinCi, 2013a, p.,43-44

${ }^{43}$ Ibid., p.,47 
De Simón Bolívar dirá que es el Modelo Bolivariano, trae el espíritu del libertador de América del sur, liberador del despotismo y constructor de una sociedad justa y nueva. Chávez, así, retoma algunos fragmentos de Bolívar, cuando escribe:

(...) [Bolivar] señala: "Tengamos presente que nuestro pueblo no es el europeo ni el americano del norte, que más bien es un compuesto de África y América, que una emanación de la Europa". Más adelante continúa delineando el elemento central de la estructura conceptual del modelo: "Nuestras leyes son funestas reliquias de todos los despotismos antiguos y modernos, que este edificio monstruoso se derribe, caiga y, apartando hasta sus ruinas, elevemos el templo a la justicia y, bajo los auspicios de su santa inspiración, dictemos un Código de leyes venezolanas" 44

A su vez, Chávez rescata la figura de Ezequiel Zamora, protagonista de la Revolución venezolana de 1858 y el Estado Federalista. Al respecto, señala:

La inspiración del general Zamora viene de las mismas raíces: robinsoniana y bolivariana. Su discurso lleva el mismo sello de la gran disyuntiva existencial. Inventó los mecanismos de la insurrección campesina de 1846, para errar y volver a inventar la forma de conducir la Revolución de $1858 .{ }^{45}$

Del mismo modo, Hugo Chávez, no solo recupera para el Socialismo del siglo XXI como saberes el árbol de las tres raíces, sino también incorpora entre sus fuentes elementos inéditos para la tradición del pensamiento de izquierda-marxista del siglo XX, como es la gesta heroica de los pueblos originarios frente a la resistencia de los españoles y el pensamiento heterodoxo de Martí y Mariátegui, junto al legado de las enseñanzas de las revoluciones socialistas del siglo $\mathrm{XX}$ :

Sólo por el socialismo lograremos los cambios verdaderos, y la revolución que hay en América Latina tiene de todo, y tiene una profunda carga socialista. Es un socialismo indo-americano, como decía Mariátegui, el gran pensador peruano; es un socialismo nuestro americano, es un socialismo martiano; es un socialismo bolivariano; es un socialismo nuevo. No es calco ni copia de nada. No hay catálogos para hacer el socialismo, hay que inventarlo; es creación heroica, dice el mismo Mariátegui. ${ }^{46}$

${ }^{44}$ Ibid., p.,49

${ }^{45}$ Ibid., p.,51

${ }^{46}$ Hugo Chávez, "Intervención del Presidente de la República Bolivariana de Venezuela en la $64^{\circ}$ Asamblea General de la Organización de las Naciones Unidas. Nueva York, 24 de noviembre de 2009”, Hugo Chávez, Aquí huele a azufre. Discursos del presidente Hugo Chávez ante la Organización de Naciones Unidas, Caracas, Ediciones MinCI, 2014b, p.,76 
No podemos desconocer ese aporte y la experiencia de la Revolución soviética, de la Revolución China, de la Revolución Cubana, mucho más cerca de nosotros en espacio y en tiempo, en carácter y en raíz. Por eso hay que estudiar mucho. Hay que leer mucho, discutir y leer las tesis socialistas, y sobre ese cúmulo de conocimientos inventar el socialismo con características venezolanas, en este tiempo y en este lugar. ${ }^{47}$

A partir de lo anterior, podemos sintetizar las ideas de la dimensión saberes latinoamericanos en el discurso de Hugo Chávez, en el siguiente diagrama:

Figura $\mathrm{N}^{\circ}$ 2. Dimensión de los saberes latinoamericanos.

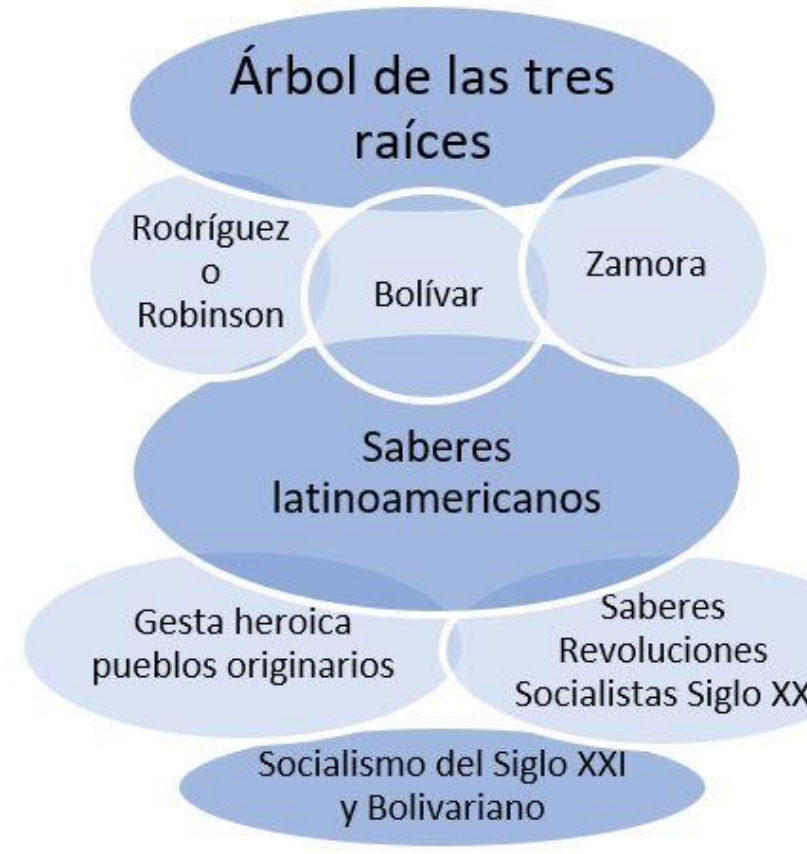

3.3- Dimensión de la economía social. Esta dimensión describe elementos de una economía popular y solidaria que integra nuevas formas de propiedad social y producción colectiva. En esta línea, Chávez sostiene la importancia de promover nuevas relaciones de producción e intercambio para el socialismo. Al respecto, afirma:

Aquí hemos iniciado experimentos como el impulso al cooperativismo y al asociativismo, a la propiedad colectiva, a la banca popular y núcleos de desarrollo endógeno, etc. Se trata de dejar atrás la lógica de funcionamiento perverso del capitalismo. Son válidas muchas experiencias como la autogestión y cogestión, la propiedad cooperativa y

${ }^{47}$ Hugo Chávez, 2011, op. cit. p.,23 
colectiva, etc. Estamos poniendo en marcha un ensayo de empresas de producción social y unidades de producción comunitaria. ${ }^{48}$

Hago un llamado a que precisemos bien, controlemos bien (...) la marcha de las empresas de producción social; allí no podemos fallar, porque del éxito en estos novedosos instrumentos productivos, del éxito de ellos dependerá la buena marcha en la construcción del socialismo ${ }^{49}$

La dimensión económica y el desarrollo de cooperativas y nuevas relaciones productivas, como la propiedad de los medios de producción en manos del colectivo, se expresan a nivel territorial a través de las comunas y la configuración de los polos de desarrollo endógeno, los cuales se integran en distintos niveles para generar nuevos modos de producción e intercambio. Así lo entiende cuando Chávez señala:

Lo económico yo lo resumiría de esta manera: la propiedad de los medios de producción en manos de la comuna; propiedad social en distintas combinaciones. Y eso tiene que ver con la creación de un nuevo modelo económico en la comuna: el modelo económico socialista, que tiene que partir desde la actividad primaria, desde la producción de materia prima. ${ }^{50}$

En este tipo de relaciones de producción e intercambio económico, es el campo donde se materializan los valores que sostienen al socialismo: intercambio justo, donde predomina la solidaridad, la cooperación, el desarrollo de bienes que cubran necesidades colectivas e individuales y no el consumo por el consumo. Entonces, la dimensión económica se articula a la dimensión ético-moral:

El socialismo distribuye la propiedad por igual. Es la propiedad tanto individual como social y colectiva. Se logra un mundo armónico, en equilibrio, como decía Bolívar [...] Nosotros defendemos la propiedad social, la propiedad del pueblo, la propiedad personal, la propiedad honesta, la propiedad de tu trabajo, la propiedad de tu vivienda, la propiedad de ti mismo, la propiedad de tus bienes personales, la propiedad familiar, la propiedad comunal. ${ }^{51}$

En la dimensión económica, Chávez destaca un elemento especialmente sensible en la actualidad y que no fue preocupación durante el siglo XX por parte de las experiencias del llamado "socialismo real", y es el respeto a la naturaleza: "Vamos a construir una economía de verdad al servicio del ser humano; eso en el capitalismo es imposible, el capitalismo beneficia a una minoría y excluye a la mayoría, y además destroza el ambiente, la vida" ${ }^{52}$, sostendrá Chávez. Así, en el socialismo bolivariano se afirma que la naturaleza -

48 Hugo Chávez, "Me convencí que el socialismo es el camino", 2013c, En http://www.puntofinal.cl/776/socialismo776.php

${ }^{49}$ Hugo Chávez, 2014a, op. cit. p., 331.

${ }^{50}$ Hugo Chávez, 2011, op. cit. p., 89

${ }^{51}$ Ibid., p. 111-112

${ }^{52}$ Hugo Chávez, 2014b, op. cit. p.,82-83 
el planeta- debe ser cuidado para las próximas generaciones, y que el capitalismo en su afán de generar ganancia, no cuida ni respeta el medio ambiente, Chávez lo señala del siguiente modo:

Hablemos de la causa, no evadamos responsabilidades, no evadamos la profundidad de este problema [el cambio climático], la causa sin duda, vuelvo al tema de todo este desastroso panorama es el sistema metabólico destructivo del capital y su modelo encarnado: el capitalismo [...] ¿Puede una tierra finita soportar un proyecto infinito? La tesis del capitalismo, el desarrollismo infinito es un modelo destructivo, aceptémoslo ${ }^{53}$

A modo de síntesis, podemos graficar esta dimensión del siguiente modo:

Figura $\mathrm{N}^{\circ} 3$.

Dimensión de la

economía social

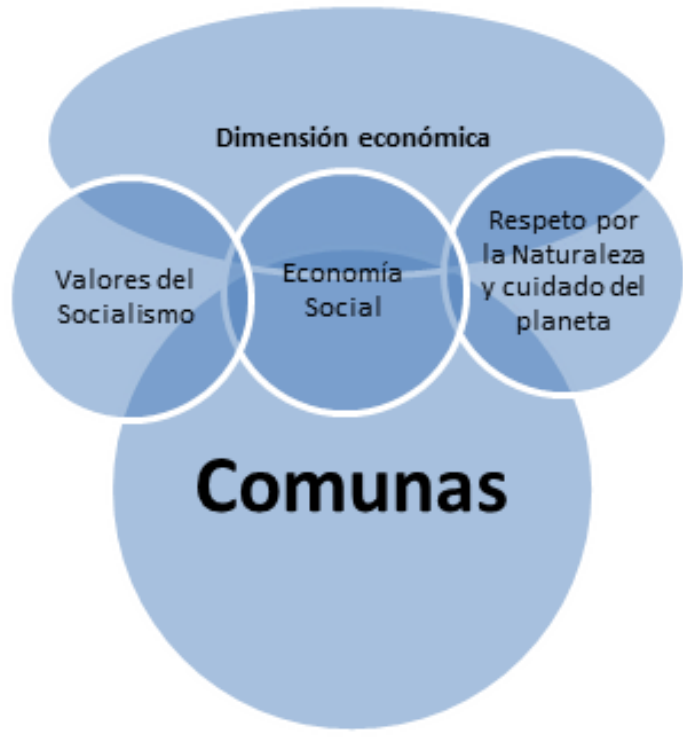

3.4 - Dimensión Política. Esta dimensión implica la concepción de una democracia participativa y protagónica, la creación de nuevos órganos políticos e institucionales de participación popular, creando canales de cercanía y colaboración en la relación institucióncomunidad, siendo ésta actor principal del proceso y de la toma de decisiones. Por ello, todas son formas en que se expresa la participación protagónica de la ciudadanía, la deliberación del pueblo frente a cuestiones que le aquejan y sus necesidades, en ese sentido, esta dimensión de democracia radical va más allá de participación formal, abstracta, busca concretar una democracia sustantiva. Chávez lo deja ver, cuando sostiene:

\footnotetext{
${ }^{53}$ Hugo Chávez, "Discurso del comandante Hugo Chávez XV Conferencia Internacional de la Organización de Naciones Unidas sobre cambio climático. Copenhague, 16 de diciembre de 2009”, Hugo Chávez, No cambiemos el clima ;Cambiemos el sistema!, Caracas, Ediciones MinCI, 2014c, p., 18-19.
} 
No es lo mismo hablar de revolución democrática que de democracia revolucionaria. El primer concepto tiene un freno, como el caballo: es revolución, pero es democrática. Es un freno conservador. El otro concepto es liberador, es como un disparo, como un caballo sin freno: democracia revolucionaria, democracia para la revolución. La democracia revolucionaria debe ser necesariamente una democracia fuerte, una democracia poderosa; debe llenarse cada día de mayor fuerza, poder; no puede ser una democracia debilucha, lánguida, insulsa, ingenua [...] Democracia poderosa, que tenga poder para transformar, que tenga poder popular en marcha; poder económico, poder social, poder popular, poder moral $^{54}$

En la democracia participativa señalada, también toman fuerza las propias enseñanzas que entrega Simón Bolívar, donde la voz del pueblo tiene un lugar central para la configuración del Estado y el gobierno, lo cual marca el sello bolivariano del pensamiento del Comandante:

Estamos ante un reto que ya Bolívar planteaba y se planteaba; por eso decía: Cómo trascender lo representativo y pasar a lo participativo; a través de qué mecanismos. Cómo resolver el problema de la proporción, de la representación para convertirla en masa participativa y no terminar siendo nosotros una asquerosa élite, una nueva clase política, alejada de esa masa anhelante que es la vida de este proyecto. ${ }^{55}$

Por otro lado, la cuestión de la democracia y el socialismo bolivariano incorpora la dimensión de los sujetos revolucionarios que impulsan y llevan adelante las tareas de construcción de una nueva sociedad. Ya se ha mencionado que tradicionalmente se asocia el sujeto revolucionario a los trabajadores o clase obrera durante el siglo XX, y que la izquierda -en su mayoría- destacó principalmente ese perfil. Sin embargo, Hugo Chávez va a poner en tela de juicio este punto y visibiliza la diversidad en la constitución de los sujetos históricos que materializan la lucha por la creación de otras relaciones sociales. De esta forma, reconoce a nuevos sujetos históricos (estudiantes, jubilados, mujeres, trabajadores, entre otros) en función del proceso concreto de lucha y autodeterminación que levanta el propio pueblo, a través de estos nuevos sujetos. Esto se observa, cuando Chávez señala:

No fue solo El Caracazo, que fue la gran explosión; no fue solo el 4 de febrero, la gran rebelión militar; o el 27 de noviembre, fueron centenares de microrrevoluciones, de huelgas, de protestas del pueblo; no era la oligarquía que protestaba, era el pueblo pobre, los desamparados, eran los estudiantes, ¿cuántos murieron? Eran los profesionales, incluso los jubilados y pensionados, los trabajadores. Hubo infinidad de microrrevoluciones o microrrebeliones en aquellos años 80 y en aquellos

\footnotetext{
${ }^{54}$ Hugo Chávez, 2011, op.cit. p.,33-34

${ }^{55}$ Hugo Chávez, 2014a, op.cit. p.,121-122 
años 90, era el Poder Constituyente buscando salida y la consiguió, conseguimos la salida. ${ }^{56}$

A continuación, podemos observar en la gráfica, una síntesis de los elementos centrales de la dimensión política:

Figura $\mathrm{N}^{\circ} 4$.

Dimensión política

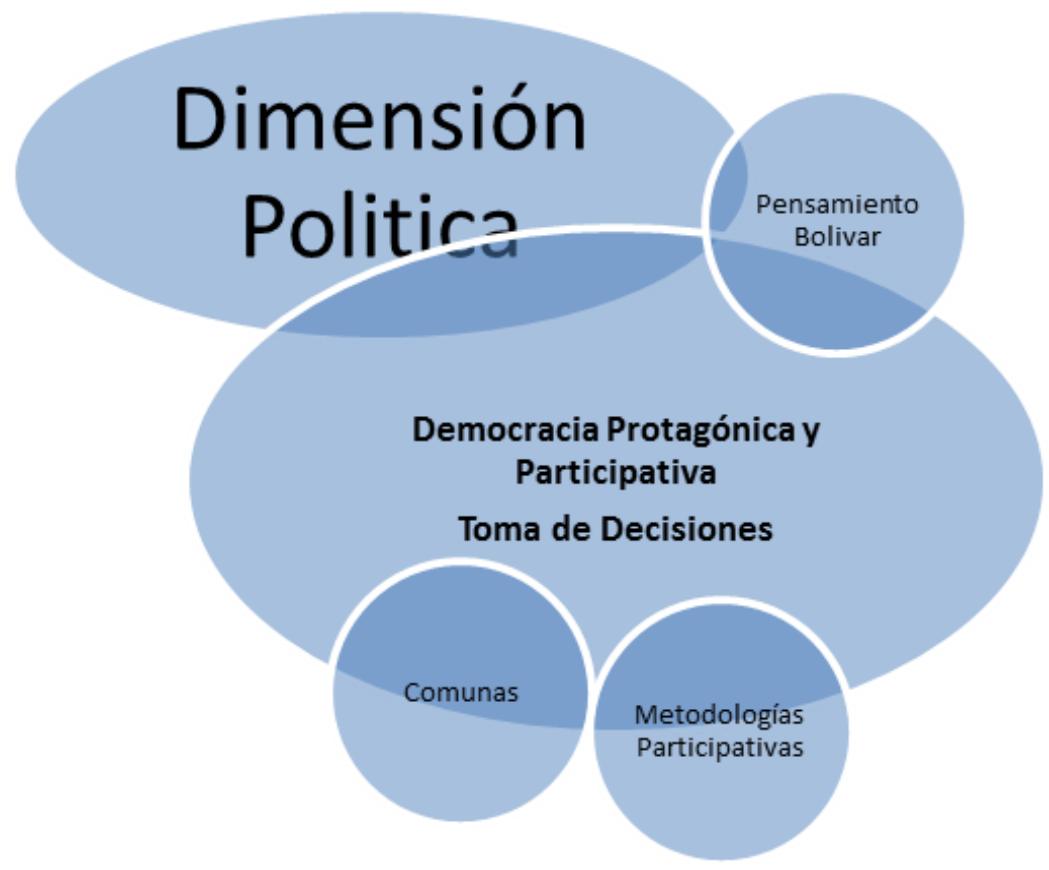

3.5.- Dimensión territorial. Esta dimensión refiere a la unidad geográfica para la construcción del socialismo bolivariano: las Comunas. Esta perspectiva se configura en un territorio delimitado geográficamente que permite concretar procesos y relaciones económicas, de poder y valores nuevos, que confrontan el modo y las relaciones sociales capitalistas: "La democracia popular bolivariana nacerá en las comunidades, y su savia benefactora se extenderá por todo el cuerpo social de la Nación" ${ }^{57}$, sostendrá Chávez. Así, la comuna es la unidad mínima o base social en la que conviven saberes, habilidades, cultura y medios de producción, todo ello a favor de la autogestión y autodeterminación. Como no existen naturalmente, Chávez y el gobierno, se empeñan en crear estas unidades con un sello que no es copia de otras experiencias, a pesar de que reconoce la inspiración en el proceso Chino de los años 50 del siglo XX en su apuesta por la comunas:

Esas comunidades socialistas, así lo entiendo yo, deben ser las comunas.

La comuna debe ser el espacio sobre el cual vamos a parir el socialismo.

El socialismo desde donde tiene que surgir es desde las bases, no se

${ }^{56}$ Ibid., p.,256
${ }^{57}$ Hugo Chávez, 2013a, op.cit. p.,78 
decreta esto; hay que crearlo. Es una creación popular, de las masas, de la nación; es una "creación heroica", decía Mariátegui. Es un parto histórico, no es desde la Presidencia de la República. [...] No habíamos nacido aquí ninguno de nosotros y ya Mao Tse Tung andaba haciendo comunas, impulsando con el pueblo bajo este principio: "La comuna popular es una creación de las masas". ¿No les parece que esta consigna de Mao deberíamos repetirla por todas partes? ${ }^{58}$

Pero Chávez, también reconoce los trazos y semilla de la comuna en los saberes y formas de organización de los pueblos originarios, rescatando elementos propios de América Latina y su pasado ancestral:

Cuando hablamos de los antecedentes de las comunas, tenemos a nuestros pueblos indígenas, sobre todo en los Andes venezolanos y en los Andes colombianos [...] Aquí nuestros aborígenes, hace miles de años, vivían en comunas, eran los comuneros de los Andes, muy arraigados a la tierra. Los caribes, del agua y del viento, vivían de otra manera; los andinos vivían arraigados, como viven normalmente, a la tierra, a la agricultura, a la montaña. ${ }^{59}$

A continuación, la figura sintetiza los elementos centrales señalados;

Figura $\mathrm{N}^{\circ}$ 5. Dimensión territorial

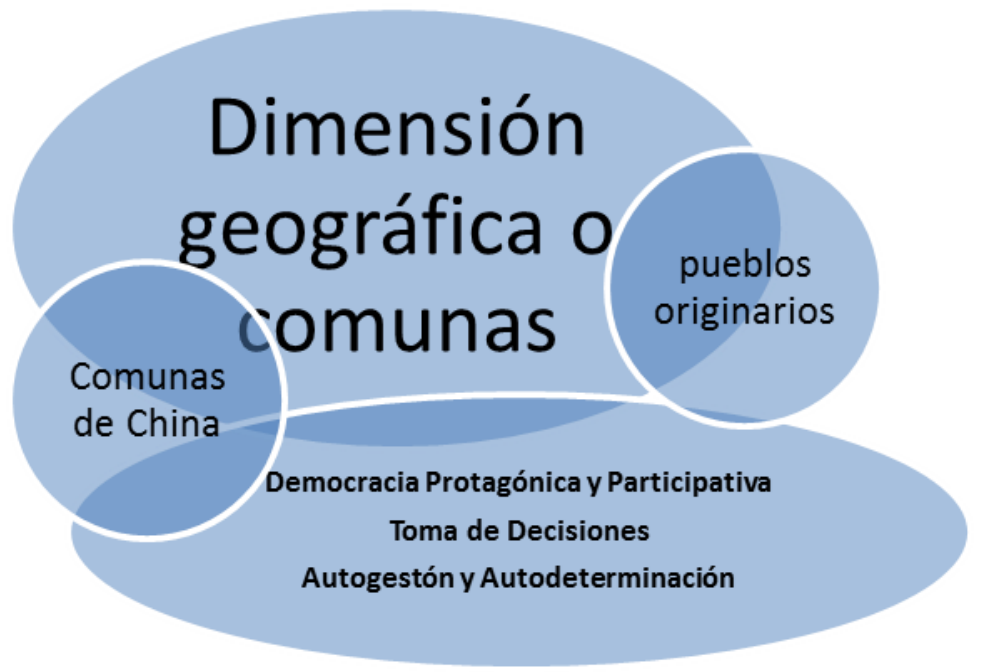

\footnotetext{
${ }^{58}$ Hugo Chávez, 2009, op. cit. p., 4-6

${ }^{59}$ Ibid., p.,5 
3.6.- Dimensión de integración latinoamericana. Esta dimensión alude a la construcción de la Patria Grande, que aparece sostenidamente en el discurso de Hugo Chávez, apelando a la necesidad de que exista paz, justicia e igualdad entre los pueblos. Sostiene la necesidad de que las diversas naciones reunidas en "la América" establezcan relaciones de solidaridad, conformen un bloque que respete la soberanía de cada una de las naciones, pero al mismo tiempo permita tomar fuerza para que la región se encuentre en igualdad de condiciones con otras latitudes y denuncie o resista las políticas neocolonialistas e imperialistas. Al respecto, Bolívar y los libertadores de los pueblos de América ya habían promovido esta alternativa como la salida del estado colonial. En ese sentido, Chávez expresa: "Revelaba el Padre Bolívar, una de sus grandes angustias: ver unidas a las naciones todas de nuestro ancho y largo continente en la Patria Grande [...] Nuestra unión era para Bolívar un pródigo fin, al que se llegaría únicamente a través de efectos sensibles y esfuerzos bien dirigidos"60. Del mismo modo, Chávez sostiene: "Pueblos del mundo, el futuro de un mundo multipolar en paz reside en nosotros. En la articulación de los pueblos mayoritarios del planeta para defendernos del nuevo colonialismo y alcanzar el equilibrio del universo que neutralice al imperialismo y a la arrogancia" ${ }^{\text {"61 }}$.

A continuación, la figura sintetiza los elementos centrales señalados;

Figura $\mathrm{N}^{\circ}$ 6. Dimensión de integración latinoamericana

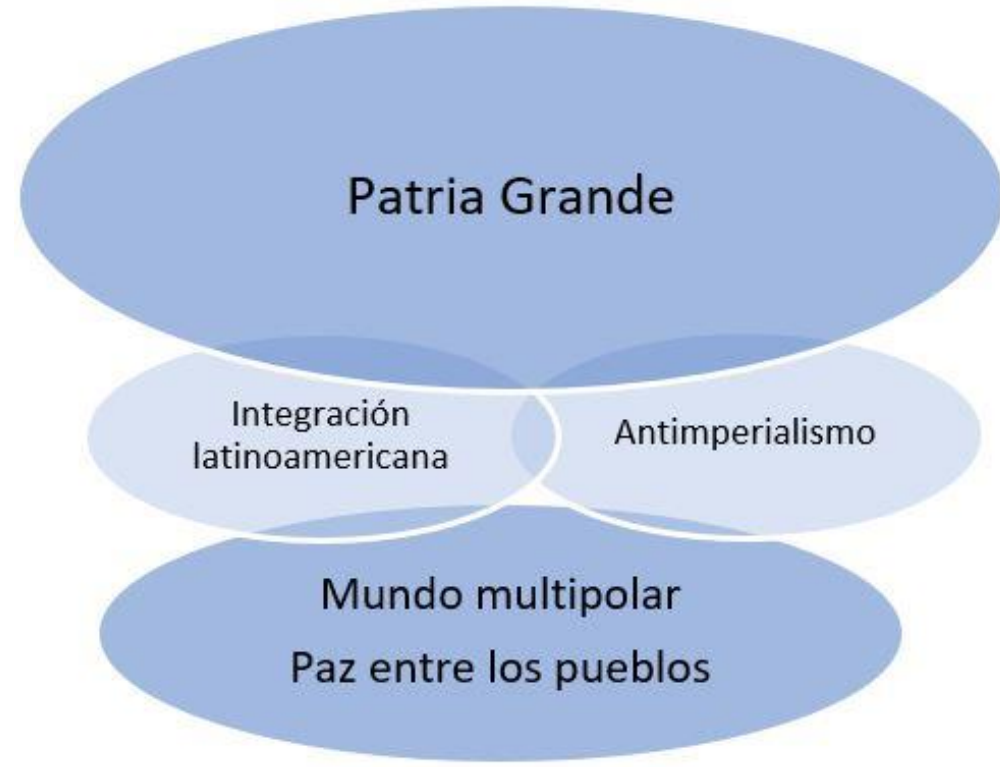

\footnotetext{
${ }^{60}$ Hugo Chávez, "Carta del comandante Chávez a los presidentes de Unasur, 2009”, Hugo Chávez, Unidad, Unidad, Unidad, Esa debe ser nuestra divisa, Caracas, Ediciones MinCi, 2014d, p., 26

${ }^{61}$ Hugo Chávez, "Intervención del Presidente de la República Bolivariana de Venezuela ante la $60^{\circ}$ Asamblea General de la Organización de las Naciones Unidas. Nueva York, 15 de septiembre de 2005”, Hugo Chávez, Nuestro compromiso con la justicia y la paz del mundo, Caracas, Correo del Orinoco, 2013b, p., 30.
} 
3.7.- Dimensión vía pacífica-institucional. Esta dimensión es uno de los sellos que caracterizan la visión de Chávez sobre la revolución y la toma del poder para avanzar hacia el socialismo, el cual se diferencia de la vía seguida en Cuba o la Unión Soviética, caracterizada por la revolución armada, violenta en la que se confrontan directamente fuerzas. Para Chávez, la paz es "un valor venezolano" por lo que la vía para avanzar y construir el socialismo es "democrática y pacífica", donde se reconoce la pluralidad de opiniones, el respeto al Estado de derecho y la institucionalidad, el diálogo, el debate de ideas y la batalla cultural. Hugo Chávez, lo dirá en los siguientes términos:

Una revolución que ya no es aquella de las columnas guerrilleras heroicas de las Sierra Maestra, de la montaña alta de Bolivia donde andaba el Che, no; ya no es ese tipo de revolución. Esta revolución es otra, ya no brota en las montañas con focos guerrilleros, no; brota de las ciudades, de las masas. Es una revolución de masas, pero es pacífica y quiere seguir siendo pacífica; es democrática, profundamente democrática. ${ }^{62}$

Por eso el socialismo en el siglo XXI que aquí resurgió como de entre los muertos es algo novedoso; tiene que ser verdaderamente nuevo, y una de las cosas esencialmente nuevas en nuestro modelo es su carácter democrático, una nueva hegemonía democrática, y eso nos obliga a nosotros no a imponer, sino a convencer [...] cómo lograrlo, cómo hacerlo. El cambio cultural. Todo esto tiene que ir impactando en ese nivel cultural. ${ }^{63}$

A continuación, la figura sintetiza los elementos centrales señalados:

Figura $N^{\circ}$ 7. Dimensión vía pacífica-institucional

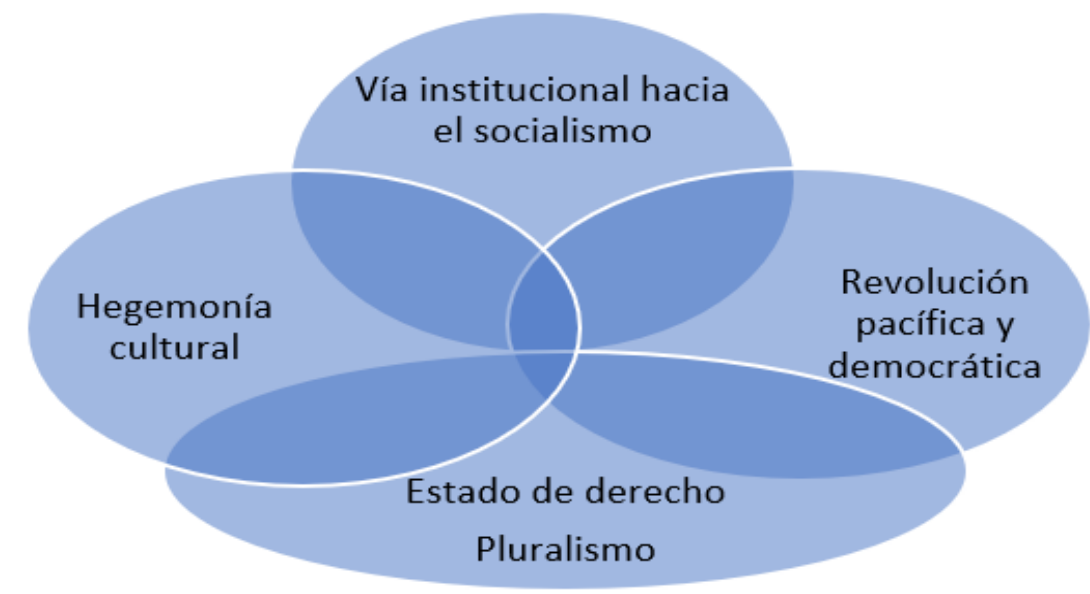

\footnotetext{
${ }^{62}$ Hugo Chávez, "Intervención del Presidente de la República Bolivariana de Venezuela en la $64^{\circ}$ Asamblea General de la Organización de las Naciones Unidas. Nueva York, 24 de noviembre de 2009", Hugo Chávez, 2014b, op. cit., p., 78

${ }^{63}$ Hugo Chávez. "I Consejo de Ministros del nuevo ciclo de la Revolución Bolivariana. Palacio de Miraflores. Caracas, 20 de octubre de 2012”, Hugo Chávez, Golpe de Timón, Caracas, Ediciones MinCi, 2012, p.,3
} 


\section{Conclusiones para el debate: Chávez y su Socialismo Bolivariano o síntesis concreta que (retoma y) supera las definiciones formales-abstractas}

A partir del proceso popular de transición al socialismo que fue tomando una forma histórica particular en Venezuela, al calor de la figura del comandante Hugo Chávez, se puede sostener que en su discurso se articula teóricamente la noción y significado del "Socialismo Bolivariano". Es un proceso que se manifiesta en: una Revolución política entendida como un proceso histórico transicional al socialismo de corte democrático, pacífico, donde un sujeto histórico subalterno emerge (como todos aquellos que sufren opresión, discriminación, explotación, esto es, la pluralidad del pueblo) y toma una posición central en un proyecto político que tiene como fin último la liberación de los pueblos. La comuna se configura como el eje central de autogestión, democratización y superación de las formas de producción y valores fomentados por el capitalismo. Al calor de la fuente inagotable de inspiración de los procesos independentistas liderados por figuras históricas de la política latinoamericana del XIX como Bolívar, Rodríguez y Zamora, además de los saberes y luchas de los pueblos originarios de América. La concepción de Hugo Chávez sobre el Socialismo Bolivariano se sintetiza en el siguiente cuadro:

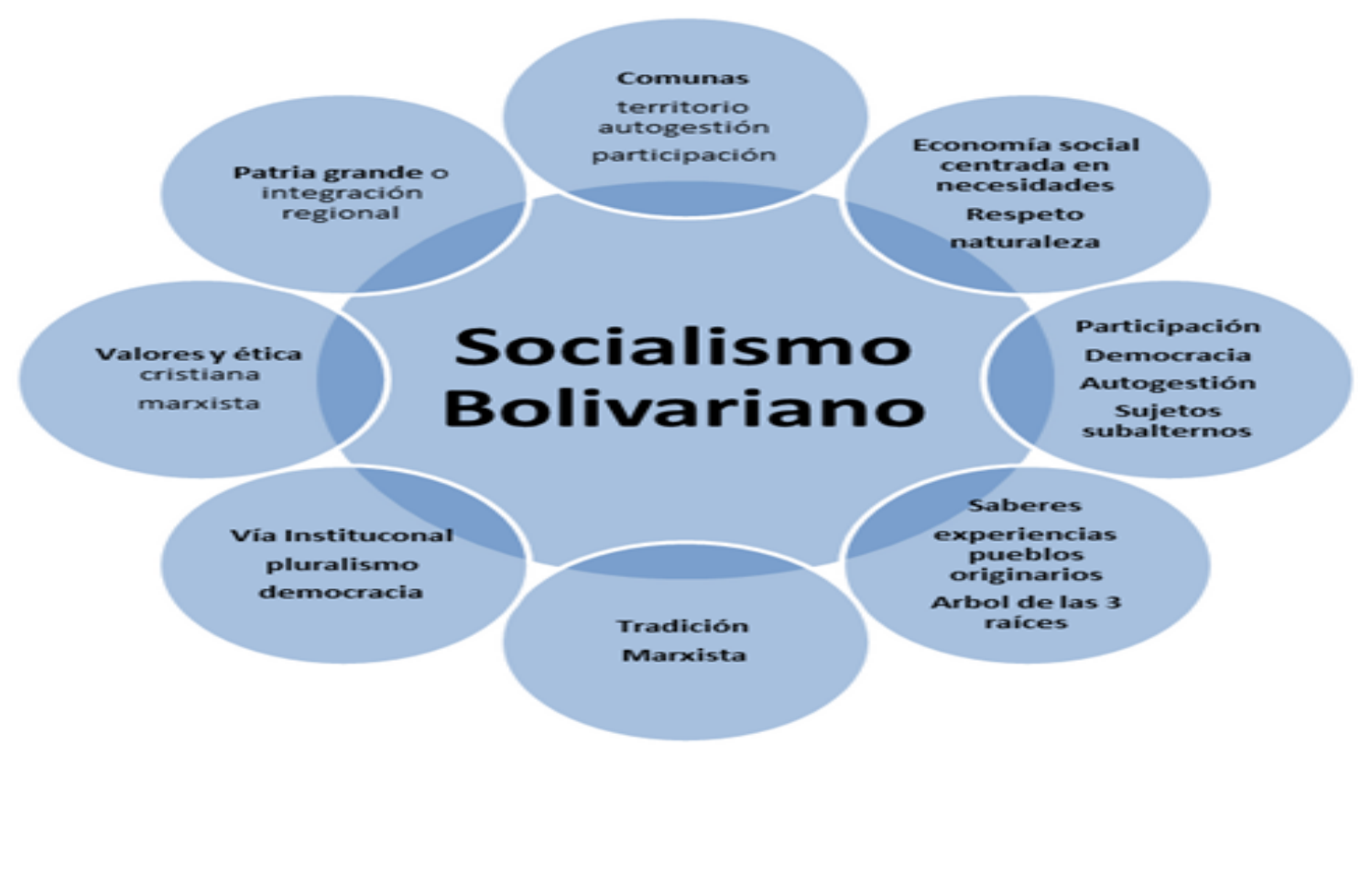

En definitiva, se puede concluir que -a nivel teórico- Hugo Chávez plantea una serie de principios que rigen el significado de "Socialismo del siglo XXI", pero en su versión 
particular o concreta como es el "Socialismo Bolivariano". En este sentido, en su visión acerca del socialismo se observan, no solo ciertas similitudes con los autores e intelectuales de referencia en este tema (revisados en el primer apartado de este artículo), sino también a partir de una apropiación de varias de estas ideas, agrega su propia contribución que le otorga un sello propio al proyecto político liderado por él en Venezuela.

Así, el análisis del marco ideológico de Hugo Chávez a la luz del proceso histórico bolivariano, permite enriquecer los principales fundamentos de su pensamiento acerca del socialismo, el cual se configura como noción a partir del rescate de varios elementos como la historia de luchas del pueblo venezolano -de profunda raíz latinoamericana -, de su cultura, de las enseñanzas de sus libertadores, de los saberes de los pueblos originarios y emanados de los procesos, aprendizajes y reflexiones de las experiencias de construcción del socialismo realizadas durante el siglo XX en el mundo (de las relaciones de producción, la idea de comuna, de los valores y ética del marxismo), del cristianismo, del protagonismo y participación del pueblo venezolano (mujeres, hombres, campesinos, trabajadores, jóvenes, ancianos, pueblos originarios), mediante una vía institucional que respete la pluralidad en la construcción del socialismo, donde y con quienes se cree una patria grande o integración regional para la liberación y apoyo mutuo, así como una economía social que no produce a costa de la devastación de la naturaleza, todo lo cual enriquece y otorga un carácter situado a las definiciones señaladas por diversos autores sobre Socialismo del Siglo XXI.

Podemos sostener que Hugo Chávez coincide con los ejes rectores planteados y que unifican las posiciones de Harnecker, Monedero, Dieterich, Mèszáros y Lebowitz, respecto a la democracia, la participación, los plurales sujetos llamados a construir una nueva sociedad, las relaciones económicas que pongan el acento en las necesidades humanas y el cuidado del planeta, revisados al comienzo de este artículo, sin embargo el pensamiento del comandante retoma la memoria histórica, aquellos elementos que han configurado la identidad nacional-regional latinoamericana y las luchas emancipatorias de los pueblos, incorporando también las matrices del pensamiento marxista (en sus diversas y plurales corrientes) y el cristianismo. Esto es lo que Hugo Chávez llama "socialismo bolivariano, socialismo indoamericano, socialismo venezolano", el cual expresa una construcción que no es copia ingenua ni simple de modelos, sino una nueva forma de comprensión socialista que sin abandonar la crítica profunda y radical a la lógica depredadora y egoísta del Capital, ya expuesta por Marx, no la agota en este autor ni en las experiencias de construcción socialista real que se inspiraron en él, incluso es capaz de realizar la crítica a las desviaciones autoritarias de estas experiencias y fortalecer la idea de la democracia y participación como ejes que sustentan nuevas relaciones sociales.

Al mismo tiempo, relee la realidad de la sociedad venezolana y retoma elementos que son propios de esa sociedad, sus pueblos, sus próceres, su cultura, su idiosincrasia, donde el cristianismo también es fundamental. Chávez, con su concepción de Socialismo Bolivariano, retoma aspectos teóricos de orden universal en diálogo con la particularidad de Venezuela y su momento histórico. Por lo tanto, en esto radica la grandeza de su pensamiento, la superación de definiciones abstractas y formales, por una perspectiva concreta, saturada de mediaciones y particularidades que le dan cuerpo y sustento a una construcción social e históricamente situada. El pensamiento de Chávez sobre el 
socialismo, no es antojadizo, arbitrario ni simple, por lo tanto, es difícil que pueda perecer en el tiempo, a pesar de las dificultades, tensiones y crisis que ha significado para el pueblo venezolano hacerlo carne. Su pensamiento, lo toman y retomarán generaciones venezolanas porque el plano teórico siempre abre el gran desafío de analizar la construcción históricoconcreta de este "Socialismo Bolivariano" en Venezuela, cuyo porvenir sigue abierto y siendo objeto, no solo de innumerables estudios y análisis de diversa índole, sino también fuente de esperanza para un "buen vivir".

\section{Referencias bibliográficas}

\section{Libros o monografías}

Mario Ayala y Pablo Quintero (comps.), Diez años de revolución en Venezuela: historia, balance y perspectivas (1999-2009). Buenos Aires, Editorial Maipue, 2009.

Luis Bilbao, Venezuela en revolución: renacimiento del socialismo, Buenos Aires, Capital Intelectual, 2008.

Iain Bruce, The Real Venezuela: Making Socialism in the 21st Century. London, Pluto Press, 2008.

Daniel Chávez, Hernán Ouviña y Mabel Thwaites Rey (Eds.), Venezuela. Lecturas urgentes desde el sur, CLACSO, 2017.

Hugo Chávez, Selección de discursos del Presidente de la República Bolivariana de Venezuela Hugo Chávez Frías, Tomo VII "Año del Salto Adelante. Hacia la construcción del Socialismo del siglo XXI”, Caracas, Ediciones de la Presidencia, 2005.

Hugo Chávez, Las comunas y los cinco frentes para la construcción del socialismo. Aló Presidente Teórico $N^{\circ}$ 1, Caracas, Ediciones MinCi, 2009.

Hugo Chávez, El socialismo del siglo XXI, Caracas, Ediciones MinCi, 2011.

Hugo Chávez, Golpe de Timón, Caracas, Ediciones MinCi, 2012.

Hugo Chávez, El libro azul, Caracas, Ediciones MinCi, 2013a.

En Hugo Chávez, Nuestro compromiso con la justicia y la paz del mundo, Caracas, Correo del Orinoco, 2013b.

Hugo Chávez, La construcción del Socialismo del Siglo XXI: discursos del Comandante Supremo ante la Asamblea Nacional (1999-2012) Tomo III (2005-2008), Caracas, Fundación Fondo Editorial de la Asamblea Nacional - Escuela de Formación Integral de la Asamblea Nacional "Dr. Carlos Escarrá Malavé" (Eficem), 2014a.

Hugo Chávez, Aquí huele a azufre. Discursos del presidente Hugo Chávez ante la Organización de Naciones Unidas, Caracas, Ediciones MinCI, 2014b.

Hugo Chávez, No cambiemos el clima ;Cambiemos el sistema!, Caracas, Ediciones MinCI, 2014c. Hugo Chávez, Unidad, Unidad, Unidad, Esa debe ser nuestra divisa, Caracas, Ediciones MinCi, 2014d.

Comisión Económica para América Latina y el Caribe (CEPAL), Protección social y generación de empleo: análisis de experiencias derivadas de programas de transferencias con corresponsabilidad, Santiago, Naciones Unidas, 2011.

Mike Gonzalez, Hugo Chavez: Socialist for the Twenty-first Century, London, Pluto Press, 2014.

Marta Harnecker, Un mundo a construir: nuevos caminos, Santiago de Chile, LOM Ediciones, 2014.

Edgardo Lander, La implosión de la Venezuela rentista, Amsterdam, Transnational Institute (TNI), 2016. 
Michael Lebowitz, The Contradictions of «Real Socialism». The Conductor and the Conducted, New York, Monthly Review Press, 2012.

Elvira Narvaja, El discurso latinoamericanista de Hugo Chávez, Buenos Aires, Biblos, 2008.

István Mészáros, El desafío y la carga del tiempo histórico: el socialismo del siglo XXI, Caracas, Vadell Hermanos Editores, 2008.

Tomas Moulian, Socialismo del siglo XXI: La quinta vía, Santiago de Chile, LOM Ediciones, 2000. Programa de las Naciones Unidas para el Desarrollo (PNUD), Informe sobre desarrollo humano 2015, Trabajo al servicio del desarrollo humano, Estados Unidos, PNUD, 2015.

Carlos Peña (comp.), Venezuela y su tradición rentista: visiones, enfoques y evidencias, Buenos Aires y Caracas, CLACSO - Universidad Central de Venezuela, 2017.

Leticia Rodríguez, El discurso de Hugo Chávez (1999-2009): Una década de hegemonía comunicacional y revival propagandístico, Memoria para optar al grado de Doctor. Departamento de Historia de la Comunicación Social, Facultad de ciencias de la información, Universidad Complutense de Madrid, 2012.

\section{Revistas y artículos en revistas}

Thays Adrián, "La metáfora conceptual en el discurso político venezolano: Rómulo Betancourt y Hugo Chávez Frías". Revista de la Asociación Latinoamericana de Estudios del Discurso, 10(1), 2010, 9-33.

Rosangel Alvarez, "El poder popular en el espacio comunal venezolano: ¿descentralización o centralismo?" Cadernos do Tempo Presente, (26), 2017, 3-27.

Nelly Arenas, "La Venezuela de Hugo Chávez: rentismo, populismo y democracia", Nueva Sociedad, 229, 2010, 76-94.

Darío Azzellini, "Economía solidaria, formas de propiedad colectiva, nacionalizaciones, empresas socialistas, co-y autogestión en Venezuela" Revista ORG \& DEMO, 10(1/2), 2010, 5-30.

Ryan Brading, "From passive to radical revolution in Venezuela's populist Project", Latin American Perspectives, 41(6), 2014, 48-64;

Rosa Corina, "Una mirada al Ordenamiento Territorial en Venezuela en el Marco del Ecosocialismo", Ciencias Espaciales, 9(1), 2016, 185-199

Irma Chumaceiro, "Las metáforas políticas en el discurso de dos líderes venezolanos: H. Chávez \& E. Mendoza" Revista Latinoamericana de Estudios del Discurso, 4(2), 2004, 91-113

Mercedes Duarte, "Funciones estratégicas de las redes de metáforas en torno a "socialismo": Un análisis interaccional del discurso político de Hugo Chávez". Revista signos, 49(90), 2016, 24-47.

Steve Ellner, "Hugo Chávez's first decade in office: Breakthroughs and shortcomings", Latin American Perspectives, 37(1), 2010, 77-96.

Laura Enríquez y Simeon Newman, "The conflicted state and agrarian transformation in pink tide Venezuela", Journal of Agrarian Change, 16(4), 2016, 594-626.

Verónica González, "De la prohibición de la tercerización hacia el fortalecimiento de los modelos socio productivos: ¿Alternativas para la transformación del Estado venezolano?”, Gaceta Laboral, 22(2), 2016, 123-143.

María García-Guadilla, "La praxis de los consejos comunales en Venezuela: ¿Poder popular o instancia clientelar?", Revista Venezolana de Economía y Ciencias Sociales, 14(1), 2008, 125-151

María García-Guadilla, "Dilemas del ecosocialismo post-neoliberal y resistencia de los movimientos sociales frente al modelo neo-extractivista en Venezuela", Revista Encuentros Latinoamericanos, 8(2), 2104, 3-47.

Margarita López-Maya y Luis Lander "El socialismo rentista de Venezuela ante la caída de los precios petroleros internacionales", Cuadernos del CENDES, 26(71), 2009, 67-87. 
José Honorio, "La política petrolera del gobierno Chávez o la redefinición del Estado ante la globalización neoliberal", Historia Actual Online, (24), 2011, 7-15.

Héctor Hurtado, "Una mirada al discurso populista de Hugo Chávez: tensiones entre la ruptura y la tradición”, Aposta. Revista de Ciencias Sociales, (66), 2015, 38-61.

Miriam Kornblith, "Venezuela: calidad de las elecciones y calidad de la democracia". América Latina Hoy, (45), 2007, 109-124.

Laura Louza, "La estrecha y necesaria relación entre independencia judicial, estado de derecho, el respeto de los derechos humanos y democracia. Venezuela como caso de estudio", Acta Sociológica, (72), 2017, 95-127.

Jesús Machado, "Participación social y consejos comunales en Venezuela", Revista Venezolana de Economía y Ciencias Sociales, 15(1), 2009, 173-185

Miguel Martínez y Rebeca Vaisberg, "La narrativa revolucionaria del Chavismo", Postdata, 19(2), 2014, 463-506.

Blanca Méndez, “Análisis Hermenéutico del discurso del expresidente Hugo Chávez: El Nuevo Mapa Estratégico a partir del contexto político Ideológico 'Contra hegemonía y Socialismo del Siglo XXI'” Reflexión Política, 17(33), 2015, 64-76

Juan Carlos Monedero, "Hacia una filosofía política del socialismo del siglo XXI. Notas desde el caso venezolano", Cuadernos del CENDES, 25(68), 2008, 71-106

Thomas Purcell, "The political economy of rentier capitalism and the limits to agrarian transformation in Venezuela", Journal of Agrarian Change, 17(2), 2017, 296-312.

Thomas Purcell, "The Political Economy of Social Production Companies in Venezuela" Latin American Perspectives, 40(3), 2013, 146-168.

Cristián Rojas, "La persistencia del lenguaje religioso en el discurso político: El caso de Hugo Chávez”, Civilizar Ciencias Sociales y Humanas, 13(24), 157-164.

Juan Romero y Yessica Quiñónez, "El pensamiento socio-político de Chávez: discurso, poder e historia (1998-2009)”, Espacio Abierto, 20(3), 2011, 519-536.

Becker Sánchez, "El rediseño socio-institucional y la acción colectiva: La experiencia venezolana de la Democracia Participativa y Protagónica del Modelo Socialista de Hugo Chávez". Espacio Abierto, 2016, 25(1).

Emiliano Terán Mantovani, "El extractivismo en la Revolución Bolivariana: "potencia energética mundial” y resistencias eco-territoriales", Iberoamericana, 15(59), 2015, 111-125.

Fuentes electrónicas o digitalizadas

Heinz Dieterich, Socialismo del Siglo XXI, 2002, En https://www.rebelion.org/docs/121968.pdf

Hugo Chávez, "Me convencí que el socialismo es el camino", 2013c, En http://www.puntofinal.cl/776/socialismo776.php 